\title{
NOTAS SOBRE LA OBRA CIENTÍFICA DE COSERIU (5)
}

\author{
José Polo \\ (Universidad Autónoma de Madrid) \\ II \\ ARQUITECTURA DE LA LENGUA \\ 2: paréntesis que desembocará en Coseriu (3) \\ $\frac{C}{1901-1925}$
}

0

Con la anterior entrega di por acabado el repaso mínimo a «cosas antiguas» relacionadas con los ejes diastrático y diafásico. Llegué, telegráficamente, hasta el final del siglo xIx. Entramos ahora de modo muy exacto en el siguiente, el que nos ha tocado vivir en mayor o menor extensión. Instalados, pues, en el siglo xx autor y lectores, me permito, tras la muestra rápida de los anteriores, seguir un orden estrictamente cronológico, cortando de manera muy precisa bien para redondear un período, bien para poner de relieve algún hecho historiográfico (como ocurrirá en la entrega siguiente, dedicada a Vicente García de Diego en relación con su planteamiento, ya clásico, de los dialectos sociales: 1926). En todo caso, se trata, cual se dijo en su momento, de crear el entorno necesario para la recta comprensión del alcance de los tempranos planteamientos de Coseriu en esta zona de estudio. Una vez enlacemos con 1954, punto de arranque coseriano, avanzaremos a buen ritmo exclusivamente dentro de la obra del maestro. 
1. Grandaent, C. H., Introducción al latín vulgar [1907], Publicaciones de la Revista de Filología Española, Ix, Centro de Estudios Históricos, Madrid, 1928 (tr. y anotación por Francisco de B. Moll): reimpresa en el csic, Madrid,

51991): «Preliminares», $\$ 1-5$, págs. 17-24 para nuestro centro de interés.

2. Aunque no pertenezcan al período tenido en cuenta, presento, como un antes, la obra de Hugo Schuchardt Der Vokalismus des Vulgärlateins (18661868), cuyos datos bibliográficos aparecen en la entrega anterior (II-2-2-3): véase, en el t. 1, la primera parte, págs. 27-65, dedicada a nociones generales sobre el latín vulgar. Y como un después, valgan: Manuel C. Díaz y Díaz, Antología del latín vulgar, Gredos, Madrid, 1950, 21962;Veikko VÄÄNÄNEN, Introducción al latín vulgar [1962], Gredos, Madrid, 1968, ${ }^{3} 1988$ (tr. de Manuel Carrión); Víctor José Herrero, Introducción al estudio de la filología latina, Gredos, Madrid, 1965, ${ }^{2} 1976$ : VII, «El latín vulgar», págs. 127-142; VIII, «El latín medieval», pági- nas 143-161; IX, «Latín cristiano y latín de liturgia», págs. 162-181; X, «El latín de los humanistas», págs. 182-200; József Herman, El latín vulgar [1967, ${ }^{3} 1975$, en francés], Ariel, Barcelona, 1997; en cubierta: «edición española[,] reelaborada y ampliada con la colaboración de Carmen Arias Abellán»; en portada: «traducción, introducción, índices y bibliografía de $\mathrm{M}^{\mathrm{a}}$ del Carmen Arias Abellán»; capítulo número 1: «El latín vulgar: cuestiones de terminología y problemas de fondo» (págs. 7-24).

\section{$B$}

3. Por A. Dauzat (véase más adelante 4; pág. 188 , nota 165 , y menciones ulteriores) he sabido del sugestivo trabajo de Arnold van GenNEP «Essai d'une théorie des langues spéciales», en Revue des Études Ethnographiques et Sociologiques, «junio-julio de 1908 (con una bibliografía de la cuestión). Este artículo ha formado, después, un capítulo del segundo tomo de Religions, Mceurs et Legendes (1909)», que es donde yo he podido consultarlo y fotocopiarlo (sin que aparezca por parte alguna el dato del tomo o del volumen de ese número de revista de 1908 y sin que, hasta el momento, me haya sido posible obtenerlos). La obra en que se recoge ese estudio lleva como subtítulo Essais d'ethnographie et de linguistique; lo edita Mercvre de France, París, 1909, ${ }^{3} 1933$; el susodicho volumen aparece como «Deuxième série»; y el trabajo mencionado, el único de la «troisième partie» (no van numerados los capítulos, dieciséis, del libro) y comprende las págs. 285-316. Posee especial interés informativo la nota bibliográfica de las págs. 290-291, con estudios de la segunda parte del siglo xix y hasta 1907 (R. LASCH, Ueber Sondersprachen und ihre Entstehung, Viena) en el s. xx. Tenemos una parte general introductoria (págs. 285-293), una primera sección, A, Langues spéciales sacrées (págs. 293299), y una segunda sección, B, Langues spéciales profanes (págs. 300-303). 
En esta última página ya anuncia otra perspectiva de estudio (no básicamente etnográfica): «Je passe à l'examen de l'aspect proprement linguistique du probleme» (al que dedica desde la mencionada 303 hasta el final, 316, esto es, aproximadamente la mitad del estudio: trabajo, pues, muy equilibrado entre lo etnográfico y lo lingüístico, haciendo justo el mencionado sublítulo Essais d'ethnographie et de linguistique). En avant-propos (pág. 7) leemos: «Les études que comprend cette deuxième série ont, comme celles de la première, paru d'abord dans des revues générales [...], ou spéciales [...]. Le texte a été remanié et mis au courant».

4. DAuzat, A., La vida del lenguaje [1910], Librería y Editorial El Ateneo, Buenos Aires, s.a. [probablemente 1946]; tr. de Luis Alfonso. Interesa especialmente a nuestro propósito el capítulo $\mathrm{Il}$, «La división de las lenguas: hablas regionales y jergas», págs. 177-192. Hay una breve introducción

(págs. 177-178); luego (págs. 178-187) se centra en cuestiones relacionadas con el eje diatópico («dialectos locales»: véase enseguida la mención a Passy), todo ello muy estudiado dentro de la llamada geografía lingüística (Gilliéron, Jaberg, Rohlfs, Alvar, etc. ); finalmente, desde la 185 hasta el final, 192, se ocupa de las jergas, de cuestiones que afectan a nuestros ejes diastrático y diafásico. En todo el capítulo, además de Gennep (véase la ficha anterior), aparece como una figura destacada (de la que se hacen varias referencias) Paul Passy, de quien presenté diversos pasajes de extraordinario interés en la entrega número 3 de esta serie (véase II-2-1-3). Voy a reproducir algunos párrafos (el introductorio y todos los de la segunda parte, esto es, los dedicados a las jergas) del susodicho capítulo, citado en más de una ocasión, pero poco conocido realmente. Hay varios casos de coma incorrecta en los que no intervengo por no hacer la lectura más engorrosa de lo que ya es:

$\frac{1}{\text { [págs.] } 177-178}$

La evolución interna de las lenguas nos llevará más tiempo que su historia externa. El fenómeno más general y más espontáneo que ofrece, es $\mathrm{el}$ de la división.

Entregada a sí misma, toda lengua que posee cierta extensión tiende a fragmentarse hasta lo infinito, por una serie de evoluciones divergentes, en tantas subdivisiones como grupos naturales existan entre sus adeptos. Estos dialectos pueden ser locales o sociales, según la feliz denominación de Paul Passy [en la nota 155 se refiere además al hecho de que Passy habla también del concepto «dialectos ocasionales» (lengua familiar opuesta a la lengua clásica): «Hoy se tiende, por lo contrario, a tomar la lengua hablada (corriente) como tipo de lenguaje; la lengua clásica se distingue de ella por fenómenos arcaicos y literarios que resumiré más adelante (cuarta parte)»: remito, en todo caso, a los textos de Passy mencionados atrás]: en otros términos, unos se constituyen en razón del espacio, y poseen un área territorial en la que cada 
uno de ellos es el único hablado con exclusión de sus vecino; y otros son propios de un medio social determinado y coexisten en una misma ciudad con otras hablas del mismo género. Los primeros son dialectos propiamente dichos, las hablas regionales; los segundos son las jergas. Aquéllos, que vamos a examinar en primer lugar, constituyen un fenómeno común a todos los tiempos y a todos los lugares: éstas, por lo contrario, son poco más o menos privativas de las grandes ciudades y sobre todo de las enormes aglomeraciones de la época actual.

187-188

Las condiciones sociales que han regido la formación de las jergas son más difíciles de determinar, pues aquí la división se produce en un mismo territorio geográfico y a causa de los medios sociales. Esta cuestión parece atraer más bien la curiosidad de los etnógrafos que de los lingüistas, quienes, hasta tiempos muy recientes, han prestado poca atención a las jergas, relegadas, muy erróneamente, a la categoría de las lenguas artificiales. En un ensayo notable [omito la nota 165], Van Gennep ha bosquejado una síntesis de las lenguas llamadas especiales y ha mostrado que el mismo fenómeno ha existido y existe en las sociedades primitivas en forma un poco diferente: las lenguas de los iniciados, los lenguajes sagrados de otros tiempos y las jergas de los oficios no son más que diversas manifestaciones de una misma necesidad social; no existe entre éstas y aquéllas ninguna diferencia de principio [en la nota 166 cita a Gennep: «Entre nosotros, las sociedades secundarias o restringidas están de ordinario constituidas por individuos que tienen la misma actividad económicamente. Pero ya el lenguaje del sacerdote presenta un carácter más complejo. Y si, gradualmente, se remonta a las sociedades semicivilizadas, se comprueba un predominio cada vez mayor del carácter sagrado de la mayoría de las lenguas especiales»].

$188-189$

Las jergas de oficios aparecen muy antiguamente y a menudo parecen tener en su origen un carácter sagrado: Van Gennep ha citado el caso de los pescadores, de los buscadores de alcanfor, de los herreros. El Ienguaje especial se individualiza vigorosamente sobre todo donde predomina el sistema de castas, como en la India, en todos los lugares en que los oficios y las profesiones constituyen sociedades particulares bien delimitadas en el seno de la sociedad general. Hay que colocar en la misma categoría lo que se llama la jerga de los ladrones, mucho menos secreta y mucho menos diferente de lo que se cree de la jerga popular - he tenido la oportunidad de explicar el porqué en otra parte [omito la nota 167]. Del mismo modo, el lenguaje infantil ofrece características análogas.

Hoy, en las grandes ciudades modernas en las que las corporaciones han desaparecido, en las que las clases y los medios sociales ya no están separados por las barreras de otros tiempos, las diversas jergas se penetran cada vez más y extienden su campo de acción [omito la nota 168]: por eso su estudio es particularmente complejo. 
El punto de vista de los lingüistas difiere necesariamente del de los etnógrafos. Aquéllos discutirán, por ejemplo, la aserción de éstos, según la cual las lenguas especiales serían creaciones voluntarias: se olvidan demasiado, al sostener esta tesis, las dificultades insalvables que habría, para individuos generalmente ignorantes, en aprender y sobre todo en crear un Ienguaje artificial [omito la nota 169]. Evidentemente el grado de conciencia aumenta rápidamente a medida que se sube en la escala social: muchas expresiones lanzadas en la jerga del teatro y de los bulevares son creaciones conscientes; la jerga de los ladrones es más inconsciente que la de los politécnicos [omito nota de asterisco]. Aun esta última, que ha dado lugar a un estudio reciente, es mucho menos artificial de lo que podría suponerse.

\section{$\frac{5}{190}$}

Pero Van Gennep ha tenido el gran mérito de haber trasladado como se merece - de una vez por todas, esperémoslo- una teoría que yo había tenido oportunidad de combatir en un terreno más reducido [omito la nota 170]: la que presentan las lenguas especiales como fenómenos excepcionales, extravagantes, debidos a la fantasía individual, y que no pueden interesar, en consecuencia, al observador científico. Esta leyenda ha contribuido, y no poco, a desviar a los lingüistas del estudio de las jergas. Por lo contrario, la formación de estas hablas es un hecho absolutamente normal, que encuentra su lugar lógico en la evolución de las lenguas. El lenguaje especial no es «ni un juego ni una diversión, sino una forma particular de un proceso lingüístico universal y fundamental». «A menudo los observadores afirman con toda buena fe que tales o cuales palabras están fabricadas de pies a cabeza, cuando investigaciones comparativas muestran que no son más que el empleo de elementos que pertenecen a la lengua común» [omito la nota 171]. El lenguaje especial «toma así su lugar en el desarrollo lingüístico normal, como corolario de la división, también normal, de las sociedades generales en las sociedades secundarias» [omito la nota 172]. Es un medio de cohesión generalmente inconsciente- para las agrupacione sociales.

\section{6 \\ 190-191}

La jerga de oficio corresponde a una necesidad social común a todos los tiempos y a todos Ios Iugares. Los lingüistas han notado ya con Bréal que una palabra que pertenece a la lengua general no tiene el mismo sentido para cada una de las agrupaciones restringidas que existen en el interior de la sociedad: al hablar de una operación - sin epíteto-, el financiero quiere designar una operación de Bolsa, el oficial una operación militar, el médico una operación quirúrgica, el maestro una operación aritmética, el negociante una operación comercial. Pero estas restricciones de sentido y estas especializaciones de palabras no bastan. La diversidad de hábitos y de necesidades sociales según los medios, la necesidad de denominar objetos o hechos especiales, de precisar actos o matices que llaman la atención diariamente - mientras que 
pasan casi inadvertidos a ojos de los demás individuos-, el sello, en fin, que la profesión imprime a la mentalidad: todos estos factores reunidos contribuyen al nacimiento de palabras y de locuciones especiales que vienen a injertarse en el árbol de la lengua común.

$191-192$

Pues una jerga no constituye, frente a sus congéneres o a la lengua de la que ha nacido, un sistema lingüístico completamente independiente, como un habla regional frente a otra habla regional: tiene en común con ella su fonética [la nota 174 dice así: «Es muy distinto cuando el lenguaje especial es el residuo de una antigua lengua extranjera, como el habla de los zíngaros y gitanos; pero el fenómeno es diferente, y ya no se trata de una jerga. Una restricción del mismo orden debe hacerse, en la antiguiedad, para ciertas lenguas especiales sagradas, que eran a menudo antiguos idiomas caídos fuera del uso general (el sánscrito en la India, etc.)»] y sus flexiones - éstas a veces simplificadas-, sus modos de formación de las palabras - de las que desarrolla más o menos tal o cual rama-y, por fin, una buena parte de su vocabulario.

\section{$\frac{8}{192}$}

Toda jerga se crea y renueva por los mismos procedimientos que la lengua ordinaria [omito la nota 175]. Las antiguas lenguas de los iniciados recurrían con preferencia al arcaísmo. Nuestras jergas modernas, por el contrario, multiplican los neologismos y precipitan las evoluciones. La jerga popular es así un verdadero francés de vanguardia, y forma la prolongación natural de la lengua natural, de la que es el equivalente exacto en un medio social inferior: palabras tomadas de las lenguas extranjeras, creaciones de palabras por metáforas, metonimia o sinécdoque, empleo de los mismos sufijos más o menos reforzados e «irradiados», emplea los mismos procedimientos de renovación lexicológica que el francés [omito la nota 176]. Estudiaré, al final de este volumen, un tipo interesante de jerga con el lenguaje deportivo, que, especializado por condiciones sociales muy particulares, posee en común con el francés, fenómenos, no solamente psicológicos, sino también literarios.

\section{$C$}

5. LeCrín, V. de, «Lengua, idioma y dialecto», en El Lenguaje [Madrid], I/1912, págs. 14-16, 37-40 y 85-95 (respectivamente, fascículos 1, 2 y 4 del referido tomo). Reproduciré los pasajes, minoría, relacionados con nuestro centro de interés (casi todo el trabajo se halla dedicado a lo que hoy denominaríamos ejes diacrónico y diatópico); prefiero no tocar un ápice en la extraña puntuación o en los aspectos ortotipográficos (falta de cursiva, etc.): 
Reciben asimismo el nombre de dialectos, las formas peculiares y características que reviste una misma lengua en cada región, en cada localidad, o en cada clase social: y así de dice, el dialecto andaluz, el dialecto gaditano, el dialecto de los barrios bajos; como se dice también, el idioma contesano, el idioma palaciego; y asimismo la lengua literaria, la lengua vulgar; confundiéndose los términos de lengua, idioma y dialecto, con el de lenguaje, que debiera ser el rectamente empleado en ejemplos como los propuestos: el lenguaje de los barrios, el lenguaje cortesano, el lenguaje literario, culto, sencillo, vulgar, severo, etc.; en su acepción de manera de expresarse, de estilo y modo de hablar y escribir de cada individuo, de cada familia, de cada clase social.

\section{$\frac{2}{38}$}

Son las lenguas el organismo viviente de la civilización, o mejor dicho, la organización del saber de los pueblos, a quienes acompaña en todas sus empresas, en todas sus conquistas, en todas sus invasiones y pacíficas colonizaciones.

Las alteraciones fonéticas y léxicas de las lenguas, son también motivadas y sostenidas en gran parte por las influencias del medio ambiente social y físico del pueblo que las habla; circunstancias externas que dan lugar al lenguaje de clases, de pueblos, de regiones y reinos. A este lenguaje propio de cada familia, de cada clase social, de cada comarca, se le ha dado en algún tiempo el nombre de idioma; y así se ha podido decir, en el idioma de palacio, en idioma matemático, en idioma de los barrios bajos. Pero hoy la significación de la palabra idioma se ha fijado para designar la lengua general, la lengua oficial de una nación.

[W. D.] Whitney, en su obra La Vida del Lenguaje [The Life and Growth of Language, Nueva York/1874, Londres/1875; según B. TliRraCinı, «W. D. Whitney y la lingüística general», $R F H, \mathrm{~V} / 1943$, págs. 105-147 (112, nota 3), «para el español, no estoy en condición de señalar nada más que la traducción anónima del primer capítulo, La vida del lenguaje: de cómo el hombre adquiere el lenguaje, Madrid, 1890»; no me ha sido posible hallar en Madrid esa traducción parcial, de la que tal vez cite Lecrín]; dice tratando de probar la diferencia convencional entre lengua y dialecto. «Lengua y dialecto son dos nombres de una misma cosa, que se emplean según se miren desde un punto de vista o desde otro. Todo conjunto de expresiones que sirve a una sociedad, por pequeña y miserable que sea, de instrumento y de medio de comunicacicón del pensamiento, es una lengua, y nadie dirá que un pueblo posee un dialecto, sino que se dice que posee una lengua. Por otra parte, no 
hay una lengua en el mundo que no podamos, sin emplear una palabra impropia, llamar dialecto, si la consideramos como un conjunto de signos lingüísticos, relativamente a otro conjunto».|l«La ciencia del lenguaje ha hecho esta distinción banal; nos ha enseñado que los signos que cada hombre emplea para expresarse constituyen su lengua o una lengua; pero no hay lengua por cultivada que pueda estar, que no sea un dialecto perteneciente a una cierta clase y a una cierta localidad grande o pequeña. El inglés escrito es una de las formas de que se sirven las clases ilustradas para un objeto determinado, y que tiene caracteres dialécticos que lo distinguen del discurso hablado de la misma clase, y aun más de las otras clases o secciones de la comunidad inglesa; cada una de estas formas tiene el mismo valor para el estudio comparado del lenguaje, que la forma llamada superior. Mas el inglés, el holandés, el sueco, etc., son los dialectos de la lengua germánica, y ésta, de la misma manera que el francés, el irlandés, el bohemio y los otros, son los dialectos de la gran familia cuyos límites hemos trazado [así la concordancia ésta/dialectos/son en el original]».

El dialecto es una lengua en determinada relación de parentesco y dependencia con otra que se llama idioma. Cuando no hay para qué tener en cuenta esa mutua relación del idioma con sus dialectos resulta improcedente el emplear tales términos; por eso juzgo impropias las expresiones dialecto cientifico, idioma matemático, dialecto vulgar, idioma cortesano. Lenguas orientales y no idiomas orientales, porque se prescinde de la idea de nación, que relaciona las lenguas como idiomas y dialectos: lenguas vivas, y no idiomas vivos, por la misma razón. Mas sí es admitido el decir lenguas extranjeras o idiomas extranjeros, esto es, propios de naciones extrañas; porque la idea de extranjero no es opuesta a la de otra nación. No se dice tampoco dialectos extranjeros, sino dialectos italianos, franceses, etc.; lo cual indica también la íntima relación existente entre el concepto de nacionalidad y el de dialecto.

$$
\frac{6}{92}
$$

Aunque los idiomas suelen ser naturalmente lenguas cultas y literarias, no es el ser tales lo característico diferencial de ellos, sino el ser la lengua general de una nación, a diferencia de las lenguas que se hablan sin carácter oficial y sólo en determinadas regiones de ella, aunque también pueden ser éstas literariamente cultivadas.

$$
\frac{7}{93-94}
$$

En castellano no tenemos un término especial para la designación de los subdialectos, que en Francia reciben el nombre del patois; pues el de jerga o germanía, no les conviene por designar un lenguaje mixto de varias lenguas, que chapurrea el vulgo en las grandes ciudades mercantiles; como el levantino, jerga o mezcla de catalán, provenzal, inglés, italiano, griego y turco, que se oye en los puertos del mediterráneo [minúscula del original]. 
Entre ciertas clases sociales, y estrictamente entre gitanos se usa una especie de lenguaje pintoresco y metafórico, con frases llenas de intencionada expresión, con palabras a veces de uso corriente, pero empleadas en sentido muy distinto del usual; lenguaje que entre nosotros recibe el nombre de caló, y es equivalente al argot francés. No falta quien haya encontrado analogía entre el caló de nuestros gitanos y el copto, y hasta quien haya buscado esa analogía con relación al sanscrito [así, forma poco usada, en el original]: pero ni aún habiendo sido el caló objeto de tales fantasías, puede ser asunto dicho lenguaje de más detenida mención en este lugar.$$
\frac{7}{95}
$$

Jerga o germanía es un lenguaje mix to de varias lenguas, que chapurrea el vulgo en poblaciones cosmopolitas.

$D$

6. Bally, Charles, El lenguaje y la vida [1913 para el primer trabajo recogido, que da título al volumen; 1926 la primera edición como tal obra conjunta; ${ }^{2}$ 1935], Losada, Buenos Aires, 1941 (tr. de Amado Alonso). Todo el libro rezuma ideas y actitudes relacionadas con nuestros ejes diastrático y diafásico.

7. Menéndez Pidal, Ramón, «Discurso del señor D. Ramón Menéndez Pidal», en Boletín de la Academia Chilena, I/1915, págs. 1-7 (agradezco la consecución de la fotocopia a mi buen amigo Ambrosio Rabanales). Texto diáfano y aleccionador que también se mueve en la zona contextual de los aspectos geográficos, sociales y estilísticos de la lengua.

8. Spitzer, Leo, Italienische Umgangssprache, Bonn y Leipzig, 1922; obra que, sin duda, no habría podido llevarse a cabo sin el clásico Hermann WunderLich, Unsere Umgangssprache (Weimar-Berlín, 1894), como tampoco habría sido posible, sin estos dos (especialmente Spitzer), la de Werner BeInHAUER, Spanische Umgangssprache (Berlín y Bonn, 1930).

9. Vossler, Karl, Filosofía del lenguaje. Ensayos [1923], Losada, Buenos Aires, 1943 [no tengo en cuenta la edición española de 1940, «menos completa», etcétera, y prácticamente desconocida]; tr. y notas de Amado Alonso y Raimundo Lida con la colaboración del autor. Interesa particularmente «Los límites de la sociolingüística», págs. 217-260. Citaré tres pasajes (dos de ellos, extensos) de esa parte del volumen (la paginación corresponde a la ${ }^{5} 1968$ ): 
No se necesitan más explicaciones para justificar especialmente una sociología omnilateral del lenguaje, tal como por lo demás ya se practica desde hace mucho con diferentes nombres, sea como geografía-lingüística, historia cultural o psicología étnica, sea como gramática histórica o comparada o como lexicología. Por cierto que Max Weber ya ha penetrado con todo éxito con los rayos luminosos de su sociología hasta los últimos reductos del alma individual: la música y la religión. En el fondo, no es más que el término de sociología lo que a muchos lingüistas les escandaliza todavía hoy como una palabrota de moda, mientras que otros, por el contrario, embriagados por el sonido de la palabra, se dejan llevar a ensalzarnos una sociología del lenguaje como cosa completamente nueva que todavía estuviera por bosquejar y por fundamentar. Así, por ejemplo, Raoul de la Grasserie con su extravagante libro Études de psychologie et de sociologie linguistiques. Des parleurs des différentes classes sociales, París, 1909. Este autor erige un monumento de papel combinando unos con otros conceptos lingüísticos y sociológicos y llenando con multitud de ejemplos del francés y de otras lenguas los cajoncitos de su sistema, que pretende ajustarse a todas las lenguas y a todos los pueblos. Lo único propiamente nuevo en esta tarea es la terminología, pues su diferenciación de las clases de estilo y de las formas idiomáticas en altas, bajas y medias era ya del todo corriente en los venerables tratados de retórica. En Raoul de la Grasserie, en lugar de las especies y ocasiones de habla, se han introducido las capas sociales, grupos y comunidades lingüísticas. Lo que antes se llamaba hablar bajo o vulgar, aquí, mediante una precipitada mezcolanza de especies de habla con especies de hombres, de usos idiomáticos con costumbres y organizaciones sociales, y de estilos con personas, se nos sirve ahora como «lengua de las clases bajas», y para colmo con un aparato greco--francés todavía más abstracto: la cataglose, que deja atónito al lector. La cataglose tiene subespecies, a saber, el estilo familiar de la oécoglose y el popular de la démoglose, y el de los delincuentes o cleptoglose y cryptoglose. El estilo elevado se llama anaglose y se nos lo quiere hacer pasar - como si Corneille o Friedrich Gottlieb Klopstock hubieran tenido sangre azul- por lengua de la aristocracia. El estilo medio y mezclado -mésoglose - se ha convertido en la lengua de la burguesía. Los inconvenientes que derivan de tan grosera confusión de estilo y lengua, lengua y hablante, condición u ocasión anímica y posición social, trata de soslayarlos el ingenioso autor injertando clases accesorias. Y ahí ha complementado la división horizontal de las capas sociales con otra vertical de los contenidos prácticos o de las necesidades espirituales. El habla del aristócrata, del burgués, del proletario — piensa él- es diferente según las circunstancias sean generales y normales, o especiales. Con esto tenemos, dentro de cada una de aquellas tres supuestas especies de habla o glosas, una orthoglose y una paraglose. Si un individuo perteneciente a la cataglose habla con otro que pertenece a la anaglose, nos resulta séboglose. Y como en la prensa diaría tenemos hoy un orden, o si se quiere un desorden, en que se barajan las palabras y estilos de todos los gloses, el cuidadoso autor ha desbrozado para él otro picadero: la métaglose. «Ce sera la presse. Elle remplit dans le monde linguistique le même rôle que les insectes dans le monde biologique pour la fécondation des fleurs». Pero como, indudablemente contagiado por la prensa, todo mortal de alguna vitalidad se toma la libertad de brincar de una glose 
a otra, pero haciéndolo sólo como individuo y, por así decirlo, bajo su propia responsabilidad, se ha establecido, junto a la métaglose de los diarios, otra métaglose individual para estos niños revoltosos del genio social del idioma, «qui consiste pour chacun à changer de glose à volonté». Y con confiada seriedad se pretende con esto tener clasificado hasta lo que trasciende de toda clasificación.

Esto ha de servirnos, no ciertamente como tema de diversión, sino como un ejemplo desalentador de los defectos y peligros típicos del tratamiento sociológico. Pues por más seria y cuidadosamente que se ponga uno a descubrir y precisar conexiones reales y palpables de la vida idiomática con lo social, acecha a cada paso la tentación de dejarse extraviar por correspondencias, semejanzas, paralelos y analogías aparentes. Quien, por ejemplo, cultiva la lexicología a la manera de Gilliéron y comprueba cómo ciertas denominaciones de determinados objetos se afirman en tal o cual comarca, cómo amplían su área y su uso y expulsan del terreno a otras denominaciones del mismo objeto (sinónimos), o cómo concurren con ellas durante algún tiempo para dejarse por fin desalojar y relevar por ellas, a la manera de la competencia mercantil, ése trabaja más o menos inconscientemente con la vacilante suposición de que las palabras son una especie de entes sociales o de personas que procuran guardar sus intereses, defendiendo o ampliando su área de dominio y sus derechos y privilegios. Pero en realidad, nunca, desde que la tierra rueda, ha habido entre dos o más palabras un pleito de derechos, ni una guerra económica, ni ninguna otra especie de hostilidad. Los hombres, no las palabras ni las lenguas en sí, son los que andan a la greña, los que ajustan tratados y alianzas. Todas las explicaciones que se nos han dado mediante estas supuestas fintas de las palabras y de las lenguas, caminan con piernas muy sospechosas. Cuántos sinónimos puede contener un mismo idioma, cuántas lenguas pueden convivir en un mismo cerebro, cuántas significaciones de un mismo cuerpo verbal pueden reunirse en él: todas éstas son preguntas que nunca se pueden contestar con exactitud y con números, porque están planteadas torcida e imprecisamente y casi siempre han resultado de un precipitado enredijo de cuestiones gramaticales con otras de sociología o de economía política o de biología. Estos problemas aparentes hay que dejarlos para esos señores que tienen tiempo sobrante para dedicarlo a psicología experimental. El pensamiento humano no es un palenque de palabras; mejor sería decir que las palabras son aparatos de gimnasia para el pensamiento.

Una palabra, una forma lingüística, una lengua fenecen sólo porque el interés espiritual del hablante se aparta de ellas, no porque otras palabras hermanas u otras lenguas enemigas las derriben en tierra, ni porque las aprieten en un rincón del mapa lingüístico, ni porque las hundan en el tufo de la cataglose o las levanten a la zona glacial de la anaglose. 
10. Holmann, J. B., El latín familiar [1925, ${ }^{3} 1950,{ }^{4} 1978$ ], CSIC (Instituto Antonio de Nebrija, Manuales y anejos de Emerita, xv), Madrid, 1958; traducido y anotado por J. Corominas. De gran interés para lo relacionado con nuestros ejes diastrático y diafásico: véase especialmente «Introducción», \$1-7, págs. 1-11.

11. Castro, Américo, El pensamiento de Cervantes, Centro de Estudios Históricos, anejo vi de Revista de Filología Española, Editorial Hernando, Madrid, 1925 (edición por la que doy las referencias); ${ }^{2} 1972$ : Noguer, Barcelona. Interesan a nuestro propósito —ejes diastrático y diafásico-, cuando menos contextualmente, los capítulos IV, «La naturaleza como principio divino e inmanente» (directamente los epígrafes Los refranes y La lengua vulgar, pági- nas 190-195 y 195-204, respectivamente), y v, «Otros temas» (todos sus epígrafes, a saber: El vulgo y el sabio, págs. 210-212; Las armas y las letras, págs. 213-219; Los españoles, págs. 219-230; Lo picaresco, págs. 230-239). Véase además la página 386 con adiciones que, en nuestro caso, afectan a texto de las págs. 212 y 219 .

12. Encuentro en la revista Cauce [Universidad de Sevilla], 18-19/1995-96, Homenaje a Amado Alonso (1896-1996), dos testimonios de interés sobre la conciencia social de los hechos lingüísticos practicada perspicazmente por el llorado investigador hispano-argentino, a saber: Carmen Saralegur: «Navarra en la obra de Amado Alonso», págs. 599-613; \$6, págs. 610-612: Alonso, precursor de metodologías posteriores con datos navarros. En su trabajo «El grupo $t r$ en España y América» (HMP, II, 1925, págs. 167-191) se refiere nuestro autor a las pronunciaciones «semiculta y rústica», al factor cultural («estudiantes»), al factor social («gentes acomodadas»), a las «clases ilustradas», a la función homogeneizadora de la ciudad y a otros conceptos que la profesora Saralegui traduce a lo que hoy día serían realidades de los ejes diastrático y diafásico (además de referirse, claro está, a las de los ejes usuales diatópico y diacrónico). $Y$ en cuanto al valor que da amado Alonso a la conciencia lingüística de los hablantes en torno a lo social, véase, ahí mismo, de Ramón Morillo-Velarde Pérez, «El método filológico de Amado Alonso y la historia de las hablas andaluzas», págs. 515-528, partic. §1, págs. 519-524. Elementos constitutivos del método filológico de Amado Alonso.

13. En El español de América. Actas del III Congreso Internacional de «El español de América» (Valladolid, 3-9 de julio de 1989), Junta de Castilla y León/Consejería de Cultura y Turismo, Valladolid, 1991, I, págs. 335-339, publica Ricardo NAvas RuIz «La oración y sus partes de Lenz: contribuciones a la lingüística y el español». En pág. 336 leemos: «La oración y sus partes mereció varias reseñas, algunas meramente informativas, de elogio o de correc- 
ción de errores [omito la nota 4], otras de más alcance. Antoine Meillet [Bulletin de la Société de Linguistique de Paris, XXII, 1921, págs. 173-174] destacó la ejemplificación de los usos sociales del lenguaje en el tratamiento de los pronombres personales en el español de América (\$156)». En efecto: el mencionado epígrafe se titula, ya desde la primera edición de la obra en 1920, Usos sociales de los pronombres personales; pero mucho antes había publicado Lenz «Zur spanisch-americanischen Formenlehre» (en Zeitschrift für romanische Philologie, XV/1891, págs. 518-522), donde, a propósito del voseo -y arrancando de Cuervo, Apuntaciones, y de Bello, Gramática-, opera con ideas reinterpretables hoy día como del ámbito social («sociolinguístico»). Otro testimonio del propio Lenz, en su Diccionario etimológico de las voces chilenas derivadas de lenguas indígenas americanas, Santiago de Chile, 1905-1910, que he manejado en la edición dirigida por Mario Ferreccio Podestá, en la misma ciudad, s.a. [1979]. En el Prólogo, págs. 7-43, crea el autor germano-chileno, págs. 20-22, una estructuración socio-estilística de los hechos del lenguaje muy expresiva de su clara conciencia "panestrática/panfásica» (en terminología que me permito improvisar). Habla, I, de estilo literario (con subdivisiones); $\mathbf{H}$, de esfera general de la vida pública; III, de lenguaje técnico de los oficios [...]; Iv, de términos vulgares de historia natural; v, de estilo familiar; vi, de lenguaje vulgar, dialecto; vil, de voces bajas que se consideran indecentes; vill, de lenguaje especial de ciertos gremios, especialmente criminales.

14. En fin, la antigüedad de las perspectivas traducibles a los ejes diastrático y diafásico (Flydal-Coseriu) no tiene límite, cabría decir. Remito una vez más al siempre aleccionador Rufino José Cuervo: en esta misma revista, 9/1993, pág. 295, y 10/1994-95, pág. 473. Preparémonos ahora para la entrada en escena de Vicente García de Diego (1926).

(continuará) 